\title{
The Association Between Non-Suicidal Self-Injury of Adolescents and the COVID-19: The Lesson We Should Notice
}

$\mathrm{Na}$ Du ( 13438381226@163.com)

The Fourth People's Hospital of Chengdu

\section{Yingjie Ouyang}

The Fourth People's Hospital of Chengdu

\section{Yu Xiao}

The Fourth People's Hospital of Chengdu

\section{Yunge Li}

The Fourth People's Hospital of Chengdu

\section{Research}

Keywords: Adolescent, COVID-19, NSSI, Post-pandemic, Risk factors

Posted Date: May 19th, 2021

DOI: https://doi.org/10.21203/rs.3.rs-512919/v1

License: (c) (i) This work is licensed under a Creative Commons Attribution 4.0 International License. Read Full License 


\section{Abstract}

Background: Non-suicidal self-injury (NSSI) in psychiatric hospitalized adolescents keeps growing after the outbreak of COVID-19. This study aims to explore the relationship between the pandemic and the NSSI among adolescents, focusing on the underlying reasons.

Methods: Through the retrospective analysis of medical record data retrieved from the electronic medical record system from January 2016 to March 2021, 609 medical records of adolescents were obtained. The main potential influencing factors were determined by the method of inductive content analysis.

Results: Among the 609 adolescents, 420 subjects had NSSI, while 189 did not. We found the percentage of NSSI adolescents in 2016 was only 29.2\% (7/24), reaching 34.5\% (29/55) in 2017, 45.7\% (42/92) in $2018,61.3 \%$ (76/124) in 2019, $92.5 \%$ (196/212) in 2020, and $95.9 \%$ (70/73) in 2021. In the Binary logistic regression model, gender $(O R=0.075)$, age $(O R=1.215)$, single parent $(O R=7.751)$, experienced trauma $(O R=2.214)$, social isolation $(O R=8.313)$, body bully $(O R=3.116)$, mobile phone overused $(O R=4.199)$, committed suicide $(O R=9.276)$, and before/after pandemic $(O R=5.421)$ were significantly associated with NSSI. When comparing the differences in influencing factors between the pre-pandemic and the postpandemic group, the results showed that experiencing trauma and suffering body bullying played less role in the appearance of NSSI, while the family constitution, relationship with parents, mobile phone use, and stressful learning have become the important factors.

Conclusions: The pandemic has increased the risk of NSSI among adolescents and changed the influencing factors of this behavior. Tailored intervention gearing toward the changed risk factors should be formulated.

\section{Background}

NSSI (Non-Suicidal Self-injury, NSSI) refers to the behaviour of directly breaking one's body tissue, such as self-harming, skin scratch, self-burning, et al.[1]. According to the definition, the purpose of implementing this behavior is not to die, but many related studies have found that the suicide risk of NSSI patients is hundreds of times higher than that of the general population [2,3]. It brings a severe burden to society and family. Some scholars have found through epidemiological investigation that the incidence rate of NSSI is $14-39 \%$ in the general adolescents population, while it is as high as $40-61 \%$ in adolescent inpatients[4]. It is estimated that by 2020 , there would be $15-30$ million teenagers with NSSI [5]. Due to its high detection rate, high risk and high repeatability, this behavior has become one of the most important public health problems in the world.

In recent years, there have been many studies aimed at exploring the causes of NSSI among adolescents. According to Chapman's Experiential Avoidance Model, individual commits NSSI to escape from unwanted emotions, which is primarily maintained by negative reinforcement [6]. Casey and colleagues revealed that adolescents are vulnerable to NSSI because of their elevated levels of impulsivity and emotional reactivity [7]. Apart from the demographic factors such as female [8], Hankin et al. found the 
dysfunctional relationships to be a significant risk factor for NSSI [9], as well as the risk factors of being bullied by peers [10] and being maltreated by parents[11].

Though the risk factors of NSSI have been studied in depth, there is little literature pointing out the composition and structural changes of these risk factors with the change of time and era. At the beginning of 2020, a sudden pandemic attacked us, which greatly changed our life, and the changed lifestyle might make people anxious[12]. Compared to adults, the special group of children and adolescents, who constitute approximately $28 \%$ of the world's population [13], have more vulnerability factors, which made their life impacted by this pandemic [14]. The latest studies reported that the pandemic made adolescents not able to meet friends, not to take outdoor activities, and not to engage in school activities, which may have continuous negative effects on the mental health of children and adolescents $[15,16]$. As reported in the above research, we feel that after the pandemic, the number of adolescents hospitalized due to mental disorder has also increased greatly. What puzzles us is that among them, the number of those who commit NSSI has also sprung up. However, the research on the reasons for this phenomenon is scarce, and little is known about the risk factors of NSSI after the pandemic. To answer these questions, we made a retrospective analysis of the medical record data of adolescent patients treated in the Clinical Psychology Department of the Fourth People's Hospital of Chengdu from 2016 to now. The purpose of our study is 1) to find out if the pandemic is associated with the increase of NSSl; 2) to find out whether the structure of risk factors of NSSI has changed after the pandemic; 3) to provide tailored measures for the prevention of NSSI in the future.

\section{Methods}

\section{Participants}

Our study was a retrospective analysis of medical record data retrieved from the electronic medical record system of our hospital. The key limitations for retrieval were the patients' age $\leqq 18$ years old and they have been admitted to the clinical psychology department of our hospital during the period from January 2016 to March 2021 (This ward was mainly responsible for treating patients with anxiety, depression and other mood disorders, etc.). After filtering out the irrelevant data (including the data of adults over 18 years old and data of repeated hospitalizations. For the latter, we only chose their latest medical record for analysis), a total of 609 medical records were obtained.

\section{Measures}

Three members in this study read through the medical records of each case, and according to their contents, they typed the information of patients' gender, age, duration of disease, the date of hospitalization, the marital status of their parents, whether they were only child, whether they had NSSI behaviour, and whether they had committed suicide into the Excel table created on the computer. To know whether the pandemic had association with the NSSI, we also added an item named "Before/after pandemic" to classify the data (Because of the pandemic, our ward was shut down at the end of January, 
and re-opened in April. The number of patients admitted in January was relatively small, and they had not been affected by the pandemic. As a result, we defined the time point as 1st April 2020, namely the patients admitted before this time were considered to be before the pandemic). The table also contained the items of might-be influencing factors of NSSI behaviour chosen by the members in this study using the method of inductive content analysis. (The specific course was described in the next section) The research has got the institutional review board (IRB) approval of the Fourth People's Hospital of Chengdu.

\section{Statistical analysis}

The study combined qualitative and quantitative analysis. For the qualitative part, the inductive content analysis was utilized to identify the main might-be influencing factors of NSSI. Three members in this study read all the 609 medical records independently and wrote as many headings as necessary to describe all possible factors. After discussing collectively, until consensus was reached, the lists of headings are grouped under higher order sub-themes. As a result, 8 sub-themes were retained as the might-be influencing factors. For quantitative data, the analysis involves descriptive statistics, with data expressed in mean \pm SD or frequency. The data of age and duration of disease were used for comparison between groups using the T-test. The chi-square test was used to determine the differences in might-be influencing factors between pre-pandemic group and post-pandemic group. Binary logistic regression models were performed using the method of Forward step wise to explore risk factors associated with NSSI among discharged adolescents, and Odds ratio (OR) and 95\% confidence interval (Cl) were obtained to show the associations between risk factors and outcomes. The sample of discharged adolescents without NSSI after the pandemic was small, and the number of factors was relatively large, resulting in the restriction of using logistic regression models, so the Pearson's correlation was used to examine the association between NSSI behaviour and might-be influencing factors in different groups. A P-value of less than 0.05 is considered statistically significant. The statistical software used for all analyses was SPSS, version 20.0 (IBM-SPSS Inc.,Armonk, NY, USA).

\section{Results}

\section{The demographic characteristics of all adolescents}

Among the 609 adolescents, 420 subjects had NSSI behaviour, while 189 did not. We classified the former into the 'NSSI group', and the latter into the 'without NSSI group'. The details of these two groups were shown in Table 1. In NSSI group, the disease duration ranged from 5 to 72 months, and the age ranged from 10 to 18 years, while the corresponding range in another group was 6 to 36 months and 12 to 18 years, respectively. 
Table 1

The demographic characteristics and risk factors of NSSI among adolescents admitted to our hospital

\begin{tabular}{|c|c|c|c|c|}
\hline Variable and assignments & $\begin{array}{l}\text { NSSI group } \\
\text { (Total } n= \\
420) \\
(\mathrm{N} \%)\end{array}$ & $\begin{array}{l}\text { Without NSSI } \\
\text { group } \\
(\text { Total } n=189) \\
(\mathrm{N} \%)\end{array}$ & OR $(95 \% \mathrm{Cl})$ & $\begin{array}{l}P \text { - } \\
\text { Value }\end{array}$ \\
\hline $\begin{array}{l}\text { Gender } \\
\text { Female (1) } \\
\text { Male (2) }\end{array}$ & $\begin{array}{l}402 \\
(95.7 \%) \\
18(4.3 \%)\end{array}$ & $\begin{array}{l}130(68.8 \%) \\
59(31.2 \%)\end{array}$ & $\begin{array}{l}0.075(0.029,0 \\
.190)\end{array}$ & $\begin{array}{l}< \\
0.001\end{array}$ \\
\hline Average age (years $\pm S D$ ) & $\begin{array}{l}15.33 \pm \\
1.74\end{array}$ & $15.37 \pm 1.75$ & $\begin{array}{l}1.215(1.022, \\
1.444)\end{array}$ & 0.028 \\
\hline $\begin{array}{l}\text { Average duration of disease } \\
\text { (months } \pm S D \text { ) }\end{array}$ & $\begin{array}{l}15.42 \pm \\
8.24\end{array}$ & $14.83 \pm 7.08$ & $\begin{array}{l}1.021 \\
1.065)\end{array}$ & 0.347 \\
\hline $\begin{array}{l}\text { Single parent } \\
\text { Yes (1) } \\
\text { No (0) }\end{array}$ & $\begin{array}{l}226 \\
(53.8 \%) \\
194 \\
(46.2 \%)\end{array}$ & $\begin{array}{l}33(17.5 \%) \\
156(82.5 \%)\end{array}$ & $\begin{array}{l}7.751 \\
(3.951,15.205)\end{array}$ & $\begin{array}{l}<.001 \\
0.00\end{array}$ \\
\hline $\begin{array}{l}\text { Only child } \\
\text { Yes (1) } \\
\text { No (0) }\end{array}$ & $\begin{array}{l}124 \\
(29.5 \%) \\
296 \\
(70.5 \%)\end{array}$ & $\begin{array}{l}77(40.7 \%) \\
112(59.3 \%)\end{array}$ & $\begin{array}{l}0.713(0.396 \\
1.287)\end{array}$ & 0.262 \\
\hline $\begin{array}{l}\text { Experienced trauma } \\
\text { Yes (1) } \\
\text { No (0) }\end{array}$ & $\begin{array}{l}75(17.9 \%) \\
345 \\
(82.1 \%)\end{array}$ & $\begin{array}{l}27(14.3 \%) \\
162(85.7 \%)\end{array}$ & $\begin{array}{l}2.214(1.043 \\
4.700)\end{array}$ & 0.039 \\
\hline $\begin{array}{l}\text { Social isolation } \\
\text { Yes (1) } \\
\text { No (0) }\end{array}$ & $\begin{array}{l}239 \\
(56.5 \%) \\
181 \\
(43.1 \%)\end{array}$ & $\begin{array}{l}24(12.7 \%) \\
165(87.3 \%)\end{array}$ & $\begin{array}{l}8.313 \\
(4.134,16.716)\end{array}$ & $\hat{0}_{0.001}$ \\
\hline $\begin{array}{l}\text { Network violence } \\
\text { Yes (1) } \\
\text { No (0) }\end{array}$ & $\begin{array}{l}115 \\
(27.4 \%) \\
305 \\
(72.6 \%)\end{array}$ & $\begin{array}{l}13(6.9 \%) \\
176(93.1 \%)\end{array}$ & $\begin{array}{l}1.082(0.434 \\
2.696)\end{array}$ & 0.865 \\
\hline $\begin{array}{l}\text { Body bully } \\
\text { Yes (1) } \\
\text { No (0) }\end{array}$ & $\begin{array}{l}109 \\
(26.0 \%) \\
311 \\
(74.0 \%)\end{array}$ & $\begin{array}{l}12(6.3 \%) \\
177(93.7 \%)\end{array}$ & $\begin{array}{l}3.116(1.311 \\
7.405)\end{array}$ & 0.010 \\
\hline
\end{tabular}




\begin{tabular}{|c|c|c|c|c|}
\hline Variable and assignments & $\begin{array}{l}\text { NSSI group } \\
\text { (Total } n= \\
420) \\
(\mathrm{N} \%)\end{array}$ & $\begin{array}{l}\text { Without NSSI } \\
\text { group } \\
\text { (Total } n=189 \text { ) } \\
(\mathrm{N} \%)\end{array}$ & OR $(95 \% \mathrm{Cl})$ & $\begin{array}{l}P \text { - } \\
\text { Value }\end{array}$ \\
\hline $\begin{array}{l}\text { Parents misunderstand } \\
\text { Yes (1) } \\
\text { No (0) }\end{array}$ & $\begin{array}{l}252 \\
(60.0 \%) \\
168 \\
(40.0 \%)\end{array}$ & $\begin{array}{l}76(40.2 \%) \\
113(59.8 \%)\end{array}$ & $\begin{array}{l}0.812(0.438 \\
1.504)\end{array}$ & 0.507 \\
\hline $\begin{array}{l}\text { Online class } \\
\text { Yes (1) } \\
\text { No (0) }\end{array}$ & $\begin{array}{l}181 \\
(43.1 \%) \\
239 \\
(56.9 \%)\end{array}$ & $\begin{array}{l}6(3.2 \%) \\
183(96.8 \%)\end{array}$ & $\begin{array}{l}1.494(0.304 \\
7.333)\end{array}$ & 0.621 \\
\hline $\begin{array}{l}\text { Learning stress } \\
\text { Yes (1) } \\
\text { No (0) }\end{array}$ & $\begin{array}{l}228 \\
(54.3 \%) \\
192 \\
(45.7 \%)\end{array}$ & $\begin{array}{l}26(13.8 \%) \\
163(86.2 \%)\end{array}$ & $\begin{array}{l}1.702(0.793 \\
3.656)\end{array}$ & 0.172 \\
\hline $\begin{array}{l}\text { Mobile phone overused } \\
\text { Yes (1) } \\
\text { No (0) }\end{array}$ & $\begin{array}{l}201 \\
(47.9 \%) \\
219 \\
(52.1 \%)\end{array}$ & $\begin{array}{l}9(4.8 \%) \\
180(95.2 \%)\end{array}$ & $\begin{array}{l}4.199 \\
(1.343,13.122)\end{array}$ & 0.014 \\
\hline $\begin{array}{l}\text { Committed suicide } \\
\text { Yes (1) } \\
\text { No (0) }\end{array}$ & $\begin{array}{l}289 \\
(68.8 \%) \\
131 \\
(31.2 \%)\end{array}$ & $\begin{array}{l}23(12.2 \%) \\
166(87.8 \%)\end{array}$ & $\begin{array}{l}9.276 \\
(4.580,18.783)\end{array}$ & $<.001$ \\
\hline $\begin{array}{l}\text { Before/after pandemic } \\
\text { After (1) } \\
\text { Before (0) } \\
\text { Constant }\end{array}$ & $\begin{array}{l}266 \\
(63.3 \%) \\
154 \\
(36.7 \%) \\
-\end{array}$ & $\begin{array}{l}14(7.4 \%) \\
175(92.6 \%) \\
-\end{array}$ & $\begin{array}{l}5.421 \\
(1.693,17.352) \\
0.073\end{array}$ & $\begin{array}{l}0.004 \\
0.073\end{array}$ \\
\hline
\end{tabular}

\section{The distribution of adolescents with NSSI in each year}

The percentage of NSSI adolescents in 2016 was only $29.2 \%$ (7/24), reaching $34.5 \%(29 / 55)$ in 2017, $45.7 \%(42 / 92)$ in $2018,61.3 \%$ (76/124) in $2019,92.5 \%$ (196/212) in 2020, and $95.9 \%(70 / 73)$ in 2021 . We found that since 2020, the proportion of adolescents with NSSI has increased dramatically. Figure 1 displayed the number of NSSI adolescents in each month from 2016 to 2021 . We can see that after the central provinces and cities resumed work gradually (due to the outbreak of COVID-19, many cities in China have stopped production), that is, from May 2020, the number of hospitalized adolescents with NSSI increased further. 


\section{The risk factors of NSSI in all discharged adolescents}

We took the NSSI behaviour as the dependent variable. 0 stands for no NSSI behaviour, and 1 for having NSSI. All the demographic characteristics, the might-be influencing factors, whether committed suicide before, and the item of "Before/after pandemic" were considered as independent variable, and their assignments were shown in Table 1. The association of risk factors with NSSI was presented in Table 1. In the Binary logistic regression model, gender $(O R=0.075)$, age $(O R=1.215)$, single parent $(O R=7.751)$, experienced trauma $(O R=2.214)$, social isolation $(O R=8.313)$, body bully $(O R=3.116)$, mobile phone overused $(O R=4.199)$, committed suicide $(O R=9.276)$, and before/after pandemic $(O R=5.421)$ were significantly associated with NSSI in hospitalized adolescents.

\section{The differences of demographic characteristics and incidence rate of might-be influencing factors between different groups}

Through the result of logistic regression model, we did demonstrate that the adolescents admitted to our hospital after the pandemic were more likely to commit NSSI. To explore the reason, we divided all subjects into two groups. One group consisted of subjects admitted to our hospital before the pandemic $(n=329)$, and another consisted of those after the pandemic $(n=280)$. The average age of all adolescents in the pre-pandemic group (15.58 \pm 1.68 years) was significantly higher than that in the postpandemic group ( $15.06 \pm 1.78$ years), and their disease duration ( $14.59 \pm 7.32$ months) was significantly shorter than that in the latter group $(16.00 \pm 8.47$ months $)(t=3.674,-2.215 ; P<0.001, P=0.027)$. We also found that the average age of adolescents with NSSI in the pre-pandemic group (15.83 \pm 1.60 years) was significantly higher than that in the post-pandemic group (15.06 \pm 1.80 years), and their disease duration (14.25 \pm 7.42 months) was significantly shorter than that in the latter group (16.10 \pm 8.61 months) $(t=$ $4.409,-2.227 ; \mathrm{P}<0.001, \mathrm{P}=0.026)$. We used the chi-square test to compare the incidence rate of all the might-be influencing factors between the NSSI adolescents in the pre-pandemic group and those in the post-pandemic group, and discovered that after the pandemic, fewer NSSI adolescents were only child $\left(X^{2}=10.408, d f=1, P=0.001\right)$, fewer ones experienced trauma $\left(X^{2}=16.793, d f=1, P<0.001\right)$, more ones experienced network violence $\left(X^{2}=20.971, d f=1, P<0.001\right)$, more ones thought their parents did not understand them $\left(X^{2}=50.554, d f=1, P<0.001\right)$, more ones took online classes $\left(X^{2}=184.149, d f=1, P<\right.$ $0.001)$, more ones thought their learning was stressful $\left(\chi^{2}=118.697, d f=1, P<0.001\right)$, more ones' parents thought their children overused mobile phones $\left(X^{2}=141.573, d f=1, P<0.001\right)$, and more ones ever committed suicide $\left(\chi^{2}=40.084, d f=1, P<0.001\right)$ (See Fig. 2 for details).

\section{The correlation between NSSI behaviour and might-be influencing factors in different groups}

We used the Pearson's correlation to analyse the relationship between NSSI and all the might-be influencing factors in the pre-pandemic group and post-pandemic group, respectively. The results are shown in Table 2. It can be said that the influencing factors in the two groups were different (see the Bold 
fonts in Table 2), which illustrated that the pandemic has changed the potential influencing factors of NSSI.

Table 2

The correlation between NSSI and might-be influencing factors in different groups

\begin{tabular}{|c|c|c|}
\hline \multirow[t]{2}{*}{ Factors } & \multicolumn{2}{|l|}{ NSSI or not } \\
\hline & Pre-pandemic $(n=329)$ & Post-pandemic $(n=280)$ \\
\hline Age & $0.140^{*}$ & -0.044 \\
\hline Gender & $-0.317^{\star \star}$ & $-0.422^{* *}$ \\
\hline Duration of disease & -0.043 & 0.050 \\
\hline Single parent & $0.349^{\star *}$ & $0.181^{\star *}$ \\
\hline Only child & -0.005 & $-0.165^{\star \star}$ \\
\hline Experienced trauma & $0.160^{\star *}$ & 0.033 \\
\hline Social isolation & $0.418^{\star \star}$ & $0.232^{\star \star}$ \\
\hline Network violence & $0.122^{*}$ & $0.128^{*}$ \\
\hline Body bully & $0.237^{\star \star}$ & 0.102 \\
\hline Parents misunderstand & 0.005 & $0.299^{\star *}$ \\
\hline Online class & - & 0.117 \\
\hline Learning stress & 0.069 & $0.323^{\star \star}$ \\
\hline Mobile phone overused & 0.088 & $0.323^{\star \star}$ \\
\hline Committed suicide & $0.422^{\star *}$ & $0.301^{\star *}$ \\
\hline
\end{tabular}

Note: ${ }^{*} \mathrm{P}<0.05 ;{ }^{* \star} \mathrm{P}<0.01 ; * \star * \mathrm{P}<0.001$

\section{Discussion}

This is an important study to understand the changing trend of NSSI behavior and its influencing factors among adolescents in psychiatric hospitals in the post-pandemic era. We found that after the outbreak of COVID-19, the number of adolescents with NSSI admitted to hospital has mushroomed, and their average age was younger, while their duration of disease was longer, which means the seriousness and difficulty of the problem. 
When analyzing the risk factors of NSSI in all adolescents admitted to our hospital, we found that females were more prone to commit NSSI behaviour, which is consistent with findings from previous studies on NSSI in adolescents $[17,18]$. We also found that parents' divorce, trauma, social isolation and body bullying are all related to adolescents' NSSI. These risk factors screened out in our study have been reported by many similar researches [19-21]. Another important risk factor in our study is the item of committed suicide, which is further supported by Wolff et al.'s study stating that more than $70 \%$ of hospitalized adolescents with NSSI ever had suicidal attempt or committed suicide [22]. It is also similar to Fox's report of an significant association between NSSI and prior suicidal thought/behaviors [23]. Different from other studies, we found that the overuse of mobile phone deemed by parents was significantly associated with adolescents' NSSI, and the outbreak of pandemic did become another risk factor of NSSI. The reasons were discussed next.

When looking at the results we have found, we cannot help asking ourselves why the pandemic aggravated the appearance of NSSI? Studies have found that the pandemic does have a particular impact on mental health, making people more prone to be anxious and depressed [24]. However, apart from the psychological pressure brought by the pandemic, what factors urge these adolescents preferred to hurt themselves repeatedly? We might find out the answer by comparing the incidence of might-be influencing factors between different groups. After the pandemic, great changes have taken place in the life structure of adolescents. First of all, due to the delay of returning to work because of the COVID-19, parents and adolescents get along with each other day and night, so they may have a greater awareness of their children's self-injury behaviour. When NSSI occurs, parents might try hard to control their child's behavior. In turn, the adolescent might think it as an intrusion, which might then lead to increased risk for NSSI [25]. Secondly, the mutual time inevitably increased their communication. As they always insist their own opinion instead of putting themselves to each other's shoes, the conflicts brought by misunderstanding might intensify. When their conflict rose to a certain level that adolescents cannot endure, they started to hurt themselves habitually to alleviate the pain caused by the contradiction [26]. That's why $72.9 \%$ of NSSI adolescents thought their parents did not understand them in the postpandemic group, and this misunderstanding was also proved to be significantly correlated with the appearance of NSSI. Thirdly, due to the pandemic, most schools had to postpone the opening date. In order not to drop the course, they carried out a new teaching mode of distant learning, which might bring some effect to adolescents. Many adolescents thought online courses' mode made it difficult to understand the teaching materials, which may further increase their anxiety on learning, which could be proved by the high rate of $74.4 \%$ in the item of learning stress in the post-pandemic group, and this factor was also found to be correlated with NSSI after the pandemic. Finally, the growing time of using electronics for online classes may also increase parents' anxiety transmitted to their children, which could be echoed by the opinions of these parents. We found that $69.9 \%$ of the NSSI adolescents' parents complained their children spent too long playing mobile phones in the post-pandemic group, which made this factor successfully squeezed into the sequence of NSSI risk factors. Except for the risk factors mentioned above, we also found that adolescents from multiple children families are more likely to have NSSI after the pandemic. The possible reason might be the competitive interaction of siblings. With the 
liberalization of the second child policy, more and more Chinese families have at least two children. The only-child NSSI adolescents in the post-pandemic group was only $24.1 \%$, which was significantly lower than that in the pre-pandemic group. Most of them had to suffer the role of taking care of their younger siblings, and according to related study, it was found that these adolescents might thought it stressful, and had the feeling of deprived love from parents [27,28], which might add fuel to the NSSI behaviour.

Regarding the structure change of risk factors of NSSI, we found that after the pandemic, experiencing trauma and suffering body bullying played less role in the appearance of NSSI, while the family constitution, relationship with parents, mobile phone use, and stressful learning have become the important factors. It is imperative to plan tailored strategies to prevent NSSI from the above situation. First of all, schools can provide relevant education for adolescents on how to cope with stress, from passive treatment of NSSI to active mental health education and guidance, thus providing a suitable environment for their healthy growth. Just as the recommendation of Singh et al., they suggested that the teachers can conduct academic and non-academic sessions in their classes, and play a role in the promotion of mental health among students[14]. Secondly, it is also vital for parents to learn how to understand and contain their children's emotions beyond paying attention to academic achievements, because parents' rejection and neglect in family rearing patterns are related to teenagers' self-injury behaviours [29]. If parents can master a reasonable way to release emotions and guide their children in time when their children have difficulties, they will avoid intensifying conflicts. As Paul once pointed out, providing health education and skill training for NSSI adolescent families will be very beneficial[30]. Regarding the problem of mobile phone using, if the parents stop their children's use in a simple and rude way, it might deteriorate their dysfunctional emotions. They are recommended to learn how to negotiate with adolescents to limit their time in the manner of understanding and respecting. In addition, if schools can contact psychotherapists or psychiatrists regularly to develop emotional processing skills like dialectical behavior therapy (DBT) for teachers and parents, it will be of great benefit to children's emotional problems [31]. The research conducted by Singh et al. also suggested that it is vital to ameliorate adolescents' access to mental health support services, and to set up collaborative networks with psychiatrists and psychologists [14].

\section{Conclusions}

In this study, we not only discovered the dramatic increase of the NSSI adolescents in the post-pandemic era, but also examined the structural change of NSSI risk factors over time. Results showed that family constitution, relationship with parents, mobile phone use, and stressful learning had significant association with NSSI after the pandemic, which were distinguishing with those before the pandemic.

\section{Limitations}

Our study should be interpreted in light of the following limitations. First, all data came from the medical records in the electronic system, it was impossible to acquire the objective risk factors in terms of scale scores. Second, the subjects in our study came from the same ward, and their representativeness would 
lead to the limitation of extending the conclusions to the wider population. There is a pressing need to plan a strong and evidenced-based follow-up study to understand the changing trend of NSSI among adolescents. Third, if we can make an in-depth analysis of the patterns and times of adolescents' selfinjury behaviors, our results will be richer.

\section{Declarations}

Ethics approval and consent to participate: The research has got the institutional review board (IRB) approval of the Fourth People's Hospitarl of Chengdu.

Consent for publication: Not applicable.

Availability of data and materials: The datasets used and/or analysed during the current study are available from the corresponding author on reasonable request.

Competing interests: The authors declare that they have no competing interests.

Funding: Funded by the Chengdu hygiene and health Committee. Award Number $\ 2019025$

Authors' contributions: D.N.: conception and design; D.N., OY.Y.J., and X.Y.: conduction; statistical analysis; L.Y.G.: administrative, technical, or material support; D.N.: drafting of the manuscript; and OY.Y.J.and X.Y.: critical revision of the manuscript for important intellectual content. All authors read and approved the final paper.

Acknowledgements: None.

\section{References}

1. Lloyd-Richardson EE. Perrine N, Dierker L. Kelley ML: Characteristics and functions of non-suicidal self-injury in a community sample of adolescents. Psychol Med 2007; 37(8):1183-92. doi:10.1017/S003329170700027X.

2. Owens D. Horrocks J, House A. Fatal and non-fatal repetition of self-harm. Systematic review. $\mathrm{Br} \mathrm{J}$ Psychiatry 2002; 181:193-9. dor:10.1192/bjp.181.3.193.

3. St Germain SA. Hooley JM: Direct and indirect forms of non-suicidal self-injury: evidence for a distinction. Psychiatry Res 2012; 197(1-2):78-84. doi:10.1016/j.psychres.2011.12.050.

4. Hurry J. Deliberate self-harm in children and adolescents. International Review of Psychiatry. 2000;12(1):31-6. 10.1080/09540260074094. doi.

5. Collins PY. Patel V, Joestl SS, et al: Grand challenges in global mental health. Nature 2011; 475(7354):27-30. doi:10.1038/475027a.

6. Chapman AL. Gratz KL, Brown MZ. Solving the puzzle of deliberate self-harm: the experiential avoidance model. Behav Res Ther 2006; 44(3):371-94. doi:10.1016/j.brat.2005.03.005. 
7. Casey BJ. Jones RM, Hare TA. The adolescent brain. Ann N Y Acad Sci 2008; 1124:111-26. doi:10.1196/annals.1440.010.

8. Bresin K. Schoenleber M: Gender differences in the prevalence of nonsuicidal self-injury: A metaanalysis. Clin Psychol Rev 2015; 38:55-64. doi:10.1016/j.cpr.2015.02.009.

9. Hankin BL. Abela JR: Nonsuicidal self-injury in adolescence: prospective rates and risk factors in a 21ํㄹ year longitudinal study. Psychiatry Res 2011; 186(1):65-70. doi:10.1016/j.psychres.2010.07.056.

10. Lereya ST. Copeland WE, Costello EJ. Wolke D: Adult mental health consequences of peer bullying and maltreatment in childhood: two cohorts in two countries. Lancet Psychiatry 2015; 2(6):524-31. doi:10.1016/S2215-0366(15)00165-0.

11. Yates TM. Carlson EA, Egeland B. A prospective study of child maltreatment and self-injurious behavior in a community sample. Dev Psychopathol 2008; 20(2):651-71. doi:10.1017/S0954579408000321.

12. Usher K. Bhullar N, Jackson D. Life in the pandemic: Social isolation and mental health. J Clin Nurs 2020; 29(15-16):2756-7. doi:10.1111/jocn.15290.

13. UNICEF. 2019. Global population of children 2100. Statista. https://www.statista.com/statistics/678737/total-number-of-children-worldwide/.

14. Singh S. Roy D, Sinha K. Parveen S, Sharma G. Joshi G: Impact of COVID-19 and lockdown on mental health of children and adolescents: A narrative review with recommendations. Psychiatry Res2020; 293: 113429. doi:10.1016/j.psychres.2020.113429.

15. Shen K. Yang Y, Wang T, et al: Diagnosis, treatment, and prevention of 2019 novel coronavirus infection in children: experts' consensus statement. World J Pediatr 2020;16(3):223-31. doi:10.1007/s12519-020-00343-7.

16. Lee J. Mental health effects of school closures during COVID-19 [published correction appears in Lancet Child Adolesc Health. 2020 Apr 17]. Lancet Child Adolesc Health. 2020;4(6):421. 10.1016/S2352-4642(20)30109-7. doi.

17. Tang J. Yang W, Ahmed NI, et al: Stressful Life Events as a Predictor for Nonsuicidal Self-Injury in Southern Chinese Adolescence: A Cross-Sectional Study. Med (Baltim) 2016; 95(9):e2637. doi:10.1097/MD.0000000000002637.

18. Barrocas AL. Hankin BL, Young JF. Abela JR: Rates of nonsuicidal self-injury in youth: age, sex, and behavioral methods in a community sample. Pediatrics 2012; 130(1):39-45. doi:10.1542/peds.20112094.

19. Hu CZ. Feng YT, Li QL, et al: The analyses of depression and correlative factors of left-behind children in Ningxia. Chinese Journal of Behavioral Medicine Brain Science 2013; 22(3):246-9. doi: 10.3760/cma.j.issn.1674-6554.2013.03.018.

20. Esposito-Smythers C. Goldstein T, Birmaher B, et al: Clinical and psychosocial correlates of nonsuicidal self-injury within a sample of children and adolescents with bipolar disorder. J Affect Disord 2010; 125(1-3):89-97. doi:10.1016/j.jad.2009.12.029. 
21. Esposito C. Bacchini D, Affuso G. Adolescent non-suicidal self-injury and its relationships with school bullying and peer rejection. Psychiatry Res 2019; 274:1-6. doi:10.1016/j.psychres.2019.02.018.

22. Wolff J. Frazier EA, Esposito-Smythers C. Burke T, Sloan E. Spirito A: Cognitive and social factors associated with NSSI and suicide attempts in psychiatrically hospitalized adolescents. J Abnorm Child Psychol 2013; 41(6):1005-13. doi:10.1007/s10802-013-9743-y.

23. Fox KR. Franklin JC, Ribeiro JD. Kleiman EM, Bentley KH. Nock MK: Meta-analysis of risk factors for nonsuicidal self-injury. Clin Psychol Rev 2015; 42:156-67. doi:10.1016/j.cpr.2015.09.002.

24. Yao H. Chen JH, Xu YF. Patients with mental health disorders in the COVID-19 epidemic. Lancet Psychiatry 2020; 7(4):e21. doi:10.1016/S2215-0366(20)30090-0.

25. Brown RC. Witt A: Social factors associated with non-suicidal self-injury (NSSI). Child Adolesc Psychiatry Ment Health 2019; 13:23. doi:10.1186/s13034-019-0284-1.

26. Nock MK. Prinstein MJ: A functional approach to the assessment of self-mutilative behavior. J Consult Clin Psychol 2004; 72(5):885-90. doi:10.1037/0022-006X.72.5.885.

27. Feinberg ME. Neiderhiser JM, Simmens S. Reiss D, Hetherington EM. Sibling comparison of differential parental treatment in adolescence: gender, self-esteem, and emotionality as mediators of the parenting-adjustment association. Child Dev 2000; 71(6):1611-28. doi:10.1111/14678624.00252 .

28. Tschan T. Lüdtke J, Schmid M. In-Albon T: Sibling relationships of female adolescents with nonsuicidal self-injury disorder in comparison to a clinical and a nonclinical control group. Child Adolesc Psychiatry Ment Health 2019; 13:15. doi:10.1186/s13034-019-0275-2.

29. Kuang LP, He XM, Zu SM, Feng XG. The effect of inappropriate parenting styles on self-injury: the mediating effect of perfectionism. Chinese Journal of Special Education. 2017;11:86-91.

30. Paul HA: Treating Self-injury: A Practical Guide, by B.W. Walsh. Child Family Behav Therapy 2013; 35(3): 271-278. doi:10.1080/07317107.2013.789375.

31. DeCou CR. Comtois KA, Landes SJ. Dialectical Behavior Therapy Is Effective for the Treatment of Suicidal Behavior: A Meta-Analysis. Behav Ther 2019; 50(1):60-72. doi:10.1016/j.beth.2018.03.009.

\section{Figures}




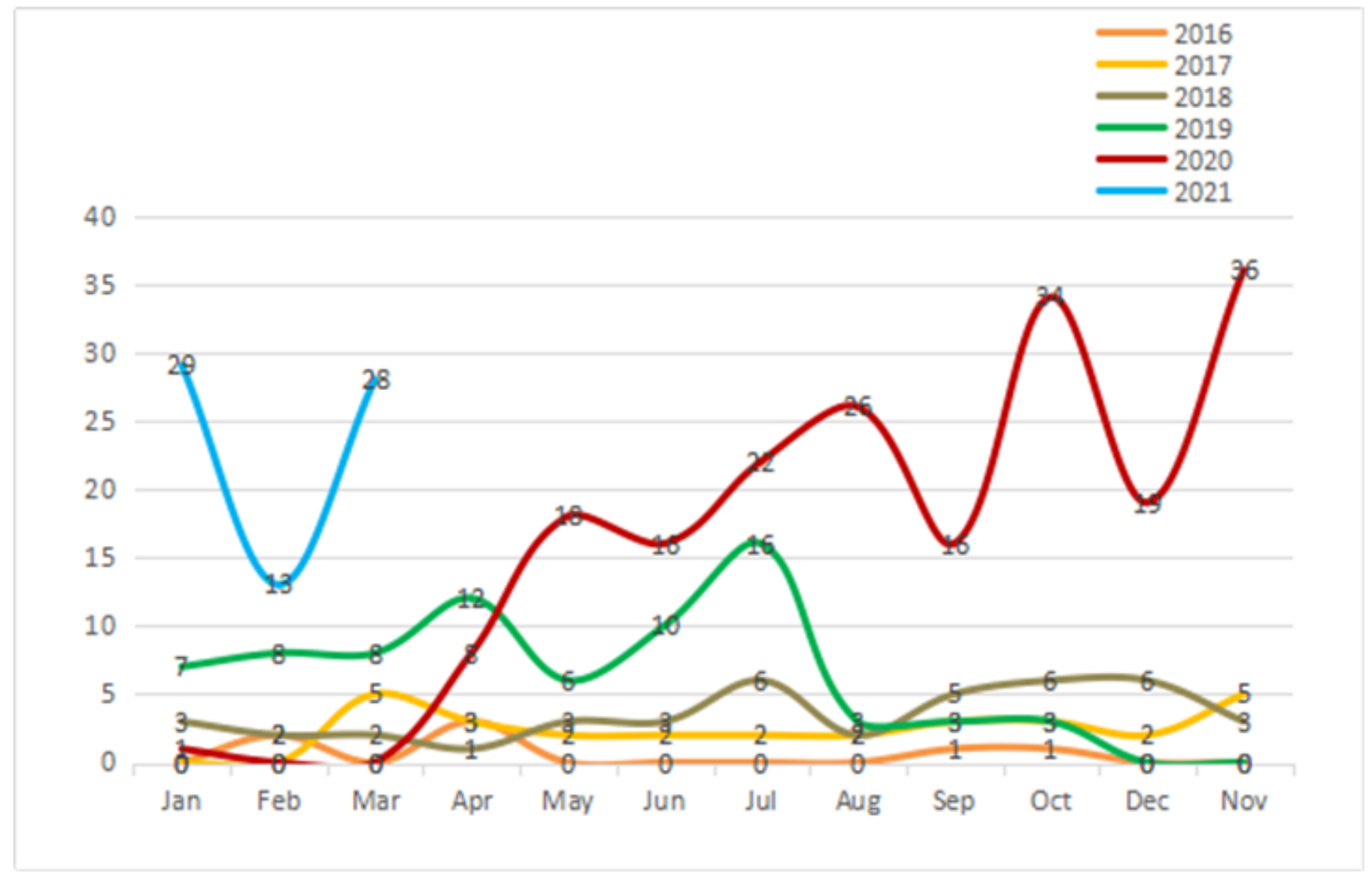

\section{Figure 1}

The number of NSSI adolescents in each month from 2016 to 2021. Note: From February 2020 to March 2020 , our ward was shut down due to the pandemic, so the number of cases in these two months was 0 . In February 2021, due to the traditional Spring Festival, the number was relatively small. 
Before epidemic

After epidemic

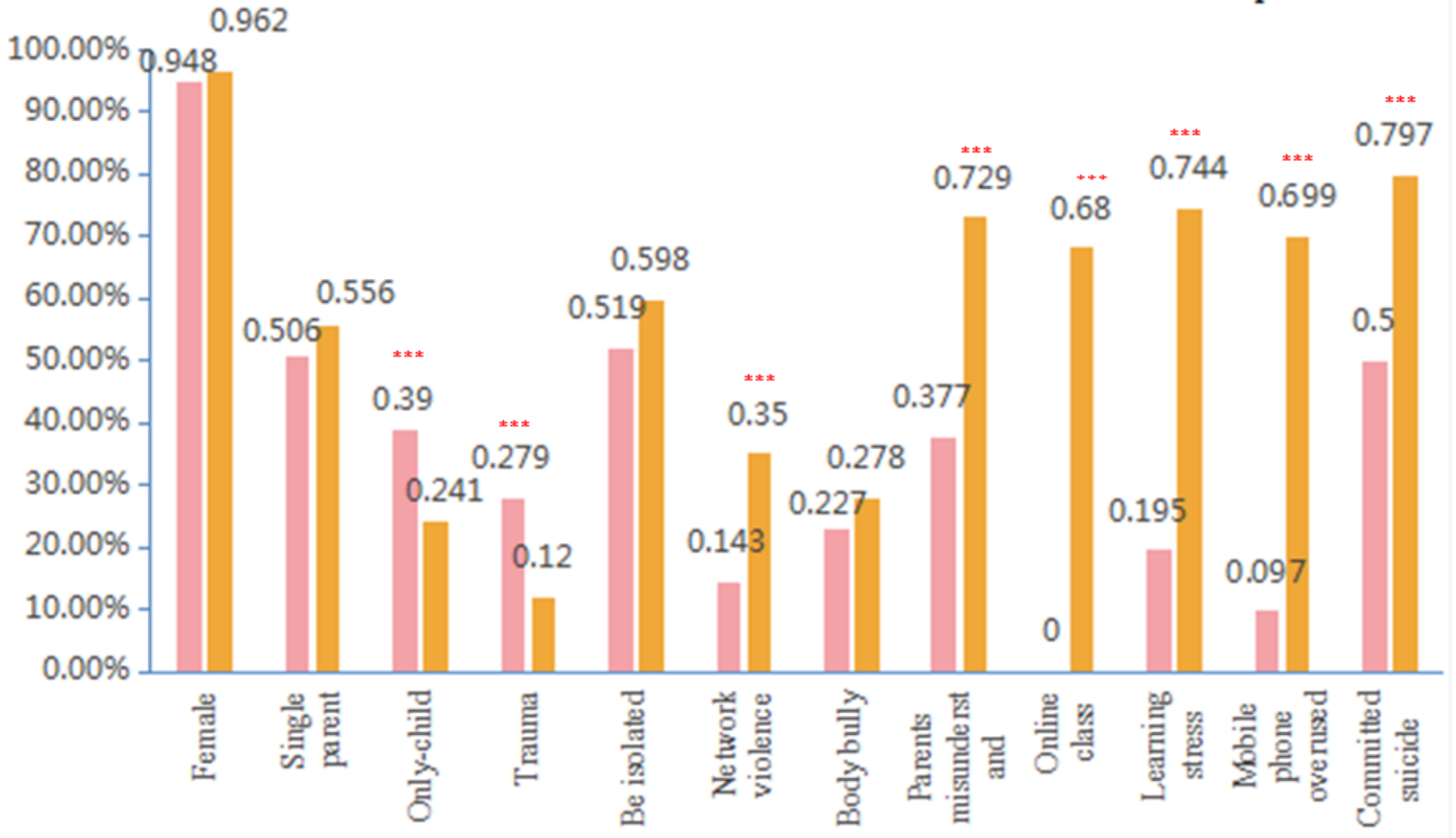

Figure 2

The comparison of incidence rates of might-be influencing factors among NSSI adolescents in different periods Note: *** stands for $\mathrm{P}<0.001$ 